\title{
Aprendizagem de modelos atômicos em atividades colaborativas com mapeamento da zona de desenvolvimento proximal em jogos móveis
}

\section{The zone of proximal development in the teaching of atomic models through a collaborative activity with mobile game}

\author{
Marcela dos Santos Barbosa ${ }^{1 *}$, José Luiz de Souza Pio ${ }^{2}$
}

\begin{abstract}
RESUMO
O aprendizado de química no primeiro ano do ensino médio tem início com o estudo do átomo, que é imprescindível para o entendimento dos demais conteúdos científicos que serão futuramente ensinados. Neste viés, ao aprender o conteúdo de atomística o aluno inicia um processo que, segundo Vygotsky, define a distância entre o nível de desenvolvimento real, determinado pela capacidade de resolver um problema sem ajuda e o Nível de desenvolvimento potencial, determinado através de resolução de um problema sob a orientação de um adulto ou em colaboração com outro aluno, conhecida como zona de desenvolvimento proximal (ZDP). Por meio da ZDP pode-se entender o curso interno do progresso cognitivo, concedendo o acesso do que já foi aprendido e ao que está em maturação. Dessa forma, com o intuito de desenvolver o aprendizado de atomística associado ao processo de desenvolvimento da ZDP, este trabalho apresenta uma abordagem para o ensino e aprendizagem de modelos atômicos utilizando como base um jogo móvel de química, desenvolvido para ser utilizado numa atividade colaborativa. Para avaliar e validar a abordagem, jogo foi aplicado junto à 16 alunos do $1^{\circ}$ ano do ensino médio de uma escola pública de Manaus/AM. Os resultados evidenciam que a atividade colaborativa com jogo móvel contribuiu para o aprendizado de modelos atômicos.
\end{abstract}

Palavras-chave: Zona de Desenvolvimento Proximal (ZDP); Modelos atômicos; Jogo móvel; Atividade colaborativa

\begin{abstract}
Chemistry learning in the first year of high school begins with the study of the atom, which is essential for understanding the other scientific contents that will be taught in the future. In this bias, when learning the content of atomistics, the student starts a process that, according to Vygotsky, would be the zone of proximal development (ZPD). Through the ZDP, it is possible to understand the internal course of cognitive progress, granting access to what has already been learned and what is maturing. Thus, in order to verify the learning of atomistics and the ZPD development process, this work presents a proposal for the teaching and learning of atomic models, using as a subsidy a mobile chemistry game, developed to be put in a collaborative activity. The game was applied to 16 students from the 1 st year of high school at a public school in Manaus/AM. The results show that the collaborative activity with mobile game contributed to the learning of atomic models.
\end{abstract}

Keywords: Proximal Development Zone (ZDP); Atomic models; Mobile game; Collaborative activity

\footnotetext{
${ }^{1}$ Universidade Federal do Amazonas *E-mail: marceladossantosbarbosa@ gmail.com

${ }^{2}$ Universidade Federal do Amazonas
} 


\section{INTRODUÇÃO}

O objetivo deste artigo é desenvolver uma abordagem pedagógica para o aprendizado de modelos atômicos por meio da caracterização da zona de desenvolvimento proximal (ZDP) numa atividade colaborativa no primeiro ano do ensino médio, por meio de um jogo móvel de química, para integrar a construção de novos conhecimentos de atomística, utilizando-se da motivação e fatores lúdicos apresentados pelo jogo.

A ZDP foi definida por Vygotsky (1978) como o intervalo entre o nível ou Zona de desenvolvimento real (ZDR), determinado pela execução individual de problemas, e a Zona de Desenvolvimento Potencial (ZDPT), caracterizado pela execução de problemas que se dá sob a orientação de alguém que detém do conhecimento a ser ensinado. Logo, ao falar que a ZDP é desenvolvida, subtende-se que as ZDPT e ZDR também serão, pois elas progridem em conjunto com a ZDP.

Jogos móveis, como o nome já diz, são jogos digitais jogados em dispositivos móveis. Esses jogos podem ser utilizados como ferramentas didáticas para auxiliar a práxis docente, devido as propriedades lúdicas e diferentes tipos de desafios que prendem a atenção do usuário. Além disso, diversos estudos comprovam a eficácia dos jogos no processo de ensino e aprendizagem de conteúdos escolares, dado que os aspectos lúdicos são atrativos e favorecem o interesse no conteúdo (NAISMITH et al., 2004).

A aprendizagem com jogo móvel poderá ser melhor alcançada durante a realização de atividades colaborativas, pois os alunos se tornam ativos no processo de aprendizagem, devido a interação e colaboração que ocorre entre pares (MOORE et al., 2009). O processo de ensino e aprendizagem do conteúdo de modelos atômicos ainda ocorre de forma tradicional, isso se dá devido ao fato do conteúdo ser histórico e o instrumento utilizado ser o livro. A apresentação somente teórica desse tema acarreta a memorização e dificuldades em assimilar os conceitos, por isso a necessidade de utilizar diferentes recursos e ferramentas didáticas.

Neste trabalho o jogo utilizado na aplicação da atividade colaborativa estabelece relações com o usuário por meio de fases, com desafios e diferentes percepções. Cada fase possui um objetivo associado e uma dificuldade. $\mathrm{O}$ jogo permite que seja 
desenvolvido, principalmente, as zonas reais e proximais, assim como apresenta a Figura 1 mostrada a seguir.

Figura 1 - Representação gráfica do desenvolvimento da zona proximal, conforme muda-se de fase no jogo móvel

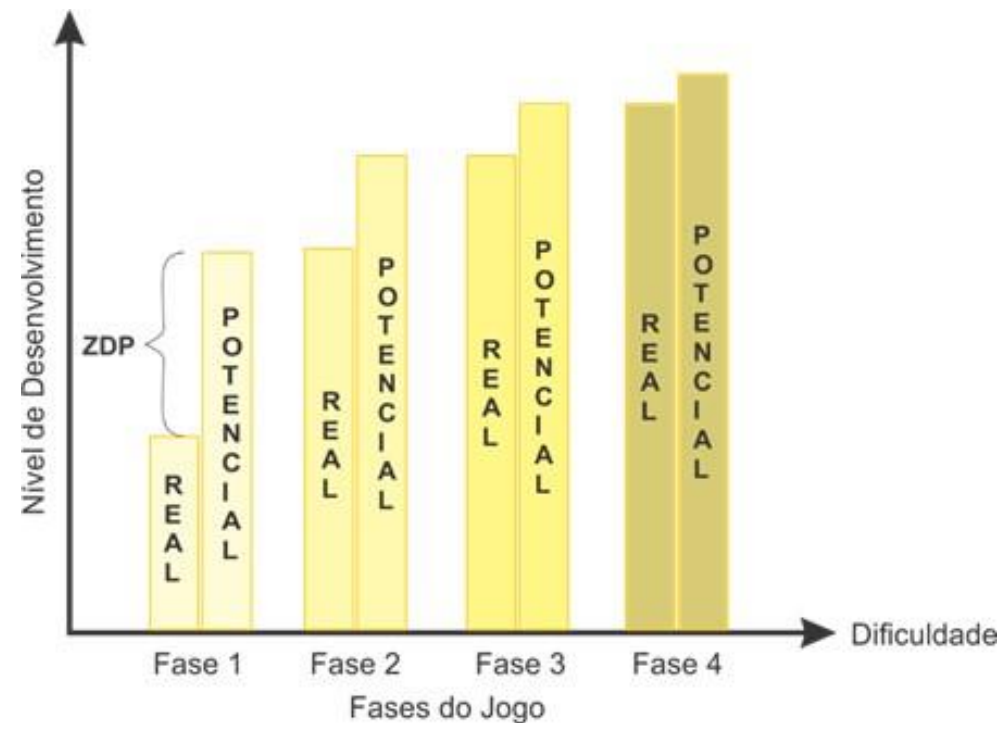

Fonte: autores

A Figura 1 revela que conforme a ZDR e ZDPT aumentam a ZDP diminui, e é explicitado que essa situação ocorrerá conforme muda-se de fase no jogo móvel. Isso se dá porque as fases promovem a interação do usuário com o jogo, por meio da construção dos modelos atômicos e relação direta com os colegas de sala, devido a interação proporcionada pela atividade colaborativa, ocasionando no desenvolvimento das zonas de aprendizagem dos sujeitos.

Dessa forma, foi desenvolvido um o jogo móvel de química para ser investigado como instrumento didático no aprendizado de modelos atômicos, durante uma atividade colaborativa, com o propósito de auxiliar no desenvolvimento das ZDP, ZDPT e a ZDR. A ludicidade e praticidade do jogo móvel e colaboração somam-se para dinamizar o processo de ensino e aprendizado do tema escolhido.

O aprendizado desperta processos de desenvolvimento que, aos poucos, farão parte das funções psicológicas cognitivas fixada no aprendiz. Constantemente as atividades e instrumentos pedagógicos, interação aluno-aluno e professor-aluno interferem na ZDP e desenvolvem a capacidade cognitiva do aluno.

Ainda segundo Oliveira (1997) quando os aprendizes precisam aprender um novo conhecimento, por exemplo, este será trabalhado na ZDP, área da percepção, análise e 
crescimento, onde é praticado por meio da aplicação de técnicas, procedimentos experimentais e mediação de instrutores ou colegas de sala, então, o novo conhecimento que está em processo de aprendizado passará a fazer parte da ZDPT até que seja aprendido e passe a fazer parte da ZDR.

\section{TRABALHOS RELACIONADOS}

Nesta sessão são apresentados trabalhos que possuem relação com atividades colaborativas e jogos móveis. Tal relação é importante, uma vez que viabiliza uma estrutura adequada para a organização da metodologia na utilização da aplicação móvel em aulas de química.

A aprendizagem colaborativa surgiu a partir de pesquisas sobre o uso de computadores como suporte para o trabalho colaborativo de aprendizagem e baseia-se nas interações sociais de indivíduos (NAISMITH et al., 2004). Geralmente é conhecida como aprendizagem com ajuda dos colegas e aprendizagem em grupo, e como regra principal tem-se o compartilhamento de ideias, conceitos e colaboração (ROMERO et al., 2012). Um indivíduo ajuda o outro conforme o seu nível de entendimento, por isso a troca de informação possibilita que eles sejam responsáveis pela própria aprendizagem, assim como dos demais membros, os alunos se tornam ativos no processo de aprendizado (MACHADO et al., 2016).

Além disso, a aprendizagem colaborativa é vista como uma abordagem que melhora o desenvolvimento de relacionamentos interpessoais, e de competências como negociação, tomada de decisão colaborativa e resolução criativa de problemas (MOURA, 2015). Os alunos aprendem através dos seus questionamentos, seguindo uma linha de raciocínio, ensinando uns aos outros e vendo como os demais aprendem (ROMERO et al., 2012).

Troncarelli e Faria (2014) definem aprendizagem colaborativa como cooperativa, pois na colaboração há cooperação, entretanto os autores dispõem de um aporte teórico relacionando as duas. Além disso, discorrem que a aprendizagem colaborativa é construtivista e uma importante alternativa para ser aplicada em sala de aula, os autores também orientam sobre como estabelecer um bom grupo de atividade e os benefícios da utilização da tecnologia na aprendizagem colaborativa.

Em relação aos jogos para dispositivos móveis, eles têm sido frequentemente explorados para melhorar o aprendizado escolar e a práxis docente, e quando eles são 
utilizados para compor atividades colaborativas em sala de aula dinamizam a dinâmica de aprendizagem. Esse fato é confirmado por Moore et al., (2009), que através de um mapeamento sistemático da literatura, menciona que jogos móveis educativos estimulam o aprendizado, e que a atividade colaborativa possibilita o amparo e a reciprocidade.

O trabalho de Barma et al.,(2015) aborda uma prática de ensino envolvendo um jogo educativo móvel para o aprendizado de física, que ele o chamou de jogo sério, apesar de não ter sido mencionado a colaboração o jogo foi utilizado pra ser trabalhado em grupo e apresentou bons resultados em detrimento da interação apresentada pelos estudantes.

\section{PROCEDIMENTO METODOLÓGICO}

A pesquisa apresentada possui uma abordagem qualitativa e descritiva por explorar o reconhecimento das subjetividades dos sujeitos (GODOY, 1995). Assim, visamos caracterizar as ZDR, ZDP e ZDPT durante uma atividade colaborativa com jogo móvel de química, no ensino de modelos atômicos, bem como explorar a contribuição do jogo móvel e da atividade colaborativa.

A metodologia foi organizada em etapas. A primeira foi a definição de um esquema didático para caracterizar as zonas de desenvolvimento de aprendizagem proposta por Vygotsky durante a atividade colaborativa e prática com o jogo móvel. Após, foi explanado como foi desenvolvido o jogo móvel de química com o propósito de desenvolver as zonas de aprendizagem, seguido da caracterização dos sujeitos da pesquisa. Após é mostrado como de seu a atividade colaborativa, com a definiçãa do tempo, regras e organização dos grupos. A última etapa foi o procedimento organizado para a coleta de dados.

\section{CARACTERIZAÇÃO DAS ZDP, ZDPT E ZDR}

Partindo do pressuposto que o aprendizado de modelos atômicos e o desenvolvimento das ZDR, ZDP e ZDPT ocorreram durante a atividade colaborativa com jogo móvel, a Figura 2 a seguir ilustra como se dará esse processo.

Figura 2 - Esquema para o desenvolvimento das zonas de aprendizagem 


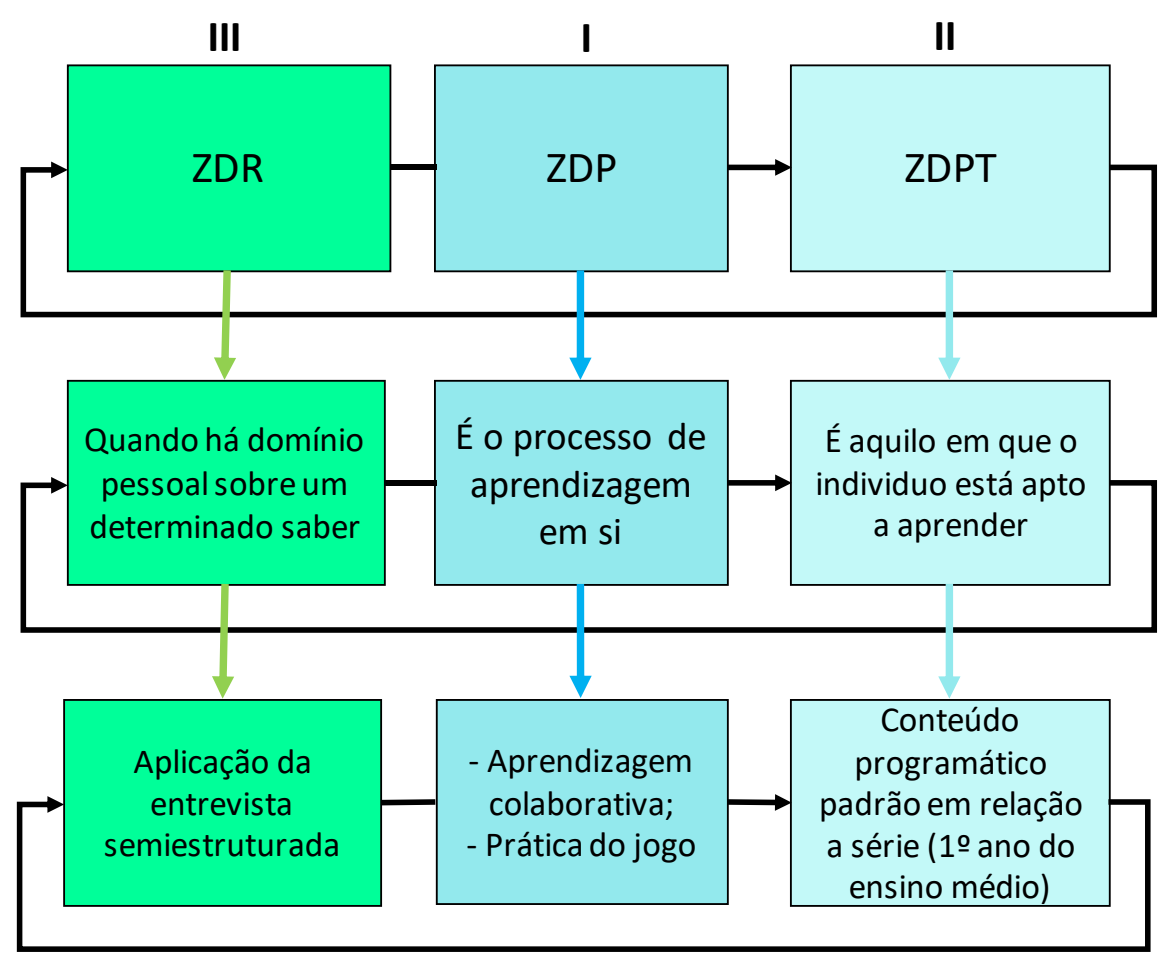

Fonte: autores

Como é observado na Figura 2, existem 9 quadrados que se relacionam entre si. A numeração (I, II, III) serve para indicar a sequência de execução para cada zona quando o aprendizado é colocado em prática. As cores iguais representam a relação da informação com uma zona específica. A seta apontada da ZDP para a ZDPT simboliza que conforme o conhecimento é colocado em prática na ZDP o aprendiz adquire habilidades que se fixaram na ZDPT, e que futuramente passará a fazer parte da ZDR.

Oliveira (1997, p. 60) afirma que “[...] a ZDP é a primeira a entrar em ação, por isso ela encontra-se entre a ZDR e a ZDPT, e nela estão presentes as funções cognitivas que ainda não amadureceram". Por isso, como observado, a ZDPT caminha junto com a ZDP. Ademais, a Figura 2 nos mostra que no decorrer da atividade colaborativa e prática com o jogo móvel, a ZDP será desenvolvida em conjunto com a ZDPT.

O conteúdo de modelos atômicos segue o cronograma escolar do primeiro ano do ensino médio, que é comum a todas as escolas públicas do Brasil, uma vez que é um conteúdo base e que serve de pré-requisito para o aprendizado de química, logo, subtendese que os alunos têm potencial para aprendê-lo, contribuindo assim com o desenvolvimento da ZDPT.

Quando o aprendizado acontecer o conhecimento novo passará a fazer parte da ZDR (ZANELLA, 1994). E para que seja verificado o nível de aprendizado acerca do 
tema investigado, antes e após a atividade colaborativa, a Figura 2 nos mostra que deve ser realizado a aplicação de uma entrevista semiestruturada.

\section{O JOGO MODELOS ATÔMICOS}

A escolha do tema do jogo se deu, sobretudo, em razão do cronograma escolar planejado para as aulas do ano de 2019, apresentado no segundo semestre de 2018, pela professora de química da turma do $1^{\circ}$ ano do ensino médio da escola Professora Adelaide Tavares de Macedo.

O jogo foi desenvolvido nos meses de outubro, novembro e dezembro de 2018, num programa chamado Construct 2, que é específico para a criação de jogos.

Ademais, em virtude do sistema operacional ANDROID apresentar um código aberto e funcionar na maioria dos dispositivos eletrônicos, com exceção de IPHONE, o jogo foi planejado para operar em aparelhos celulares com esse tipo de sistema. A APK para instalação do jogo encontra-se disponível no site https://jogosdeciencias.wixsite.com/mobile.

A seguir serão apresentados o menu fases e os templates da fase de treino do jogo, necessários para favorecer o aprendizado de atomística por meio da construção dos modelos atômicos, começando pela explanação do modelo de Dalton, seguido da elaboração do mais básico, o de Thomson, e finalizando com o mais complexo, o de Bohr.

Na Figura 3 é apresentado a tela de menu fases do jogo, que é dividida em duas fases. Para este trabalho focaremos apenas nas fases de treino.

Figura 3 - Template de apresentação do menu fases

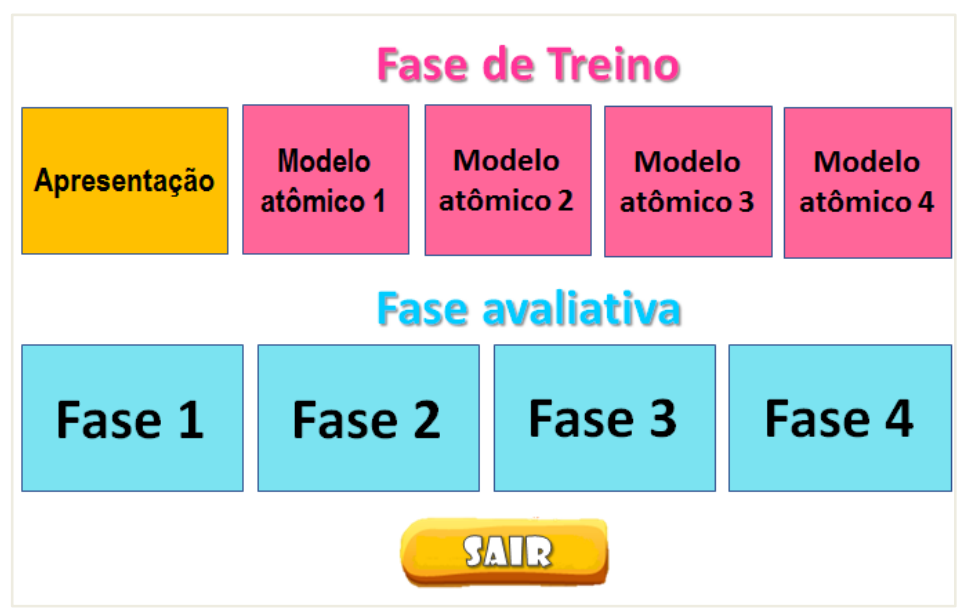

Fonte: autores 
As fases foram organizadas de acordo com a ordem de descoberta de cada modelo durante o período histórico. Brown et al. (2005) diz que a teoria do modelo atômico de Dalton serviu de base para que Thomson planejasse o modelo de pudim de passas e deduzisse a existência de partículas minúsculas incrustadas no átomo, e, consequentemente, serviu de base teórica para que Rutherford desenvolvesse o modelo do sistema planetário, que consequentemente serviu de suporte teórico e investigativo para o estudo aprofundado do modelo atômico proposto por Bohr.

A Figura 4 a seguir corresponde ao modelo atômico 1 ou modelo de Dalton, também conhecido como o modelo da bola de bilhar. Nessa fase só há informações a respeito do modelo atômico proposto por Dalton.

Figura 4 - Template do modelo atômico 1

\section{WENDCDASES}

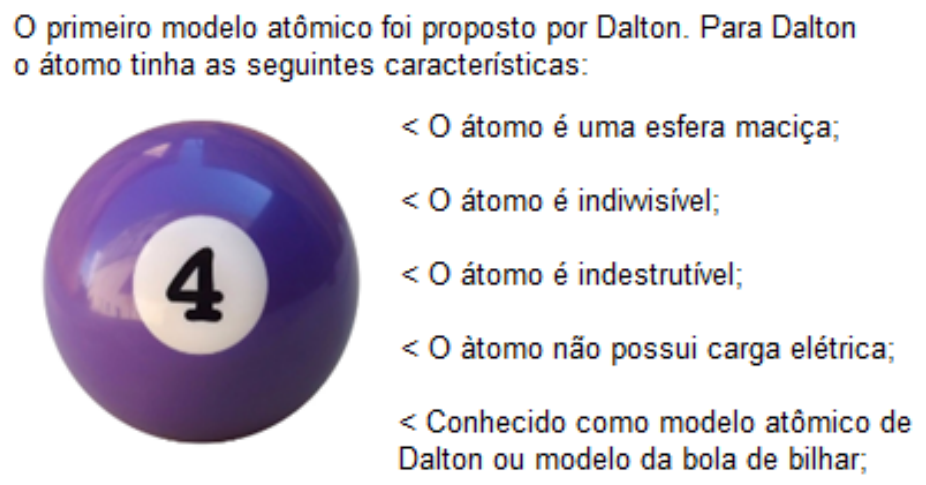

Fonte: autores

A Figura 5 a seguir, mostra o modelo atômico 2, conhecido como pudim de passas ou modelo de Thomson, nessa fase os usuários começaram a interagir com uma estrutura atômica.

Figura 5 - Template do modelo atômico 2 
Construa o modelo de átomo proposto por Thomson,

colocando as partículas positivas e negativas no lugar correto.

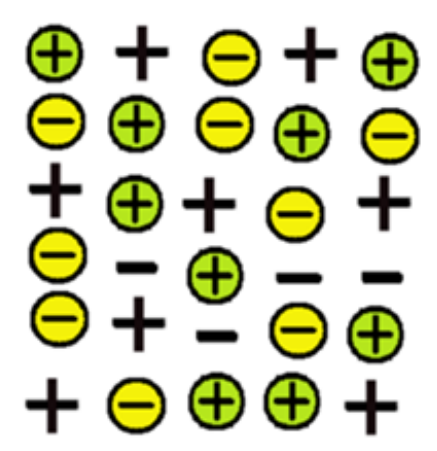

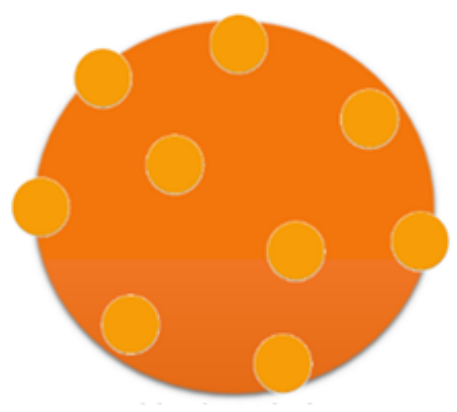

Modelo do pudim de passas

Fonte: autores

Para melhor entendimento no modelo de Thomson, e Figura 5, quando se interage com o jogo é necessário que os usuários selecionem com o dedo e arraste para a área laranja os componentes positivos e negativos. Há dois efeitos nessa fase para fazer com que o aprendiz entenda se está colocando as partículas nos locais corretos e para que ele questione sua ação, a primeira é um efeito de "brilho" que indica que a partícula foi colocada no local correto, o segundo efeito é o da "destruição", ou seja, se o usuário errar no posicionamento a partícula será destruída.

A mesma situação desenrola-se para o modelo atômico 3, conhecido como modelo de Rutherford, como mostra a Figura 6 a seguir.

Figura 6 - Template do modelo atômico 3

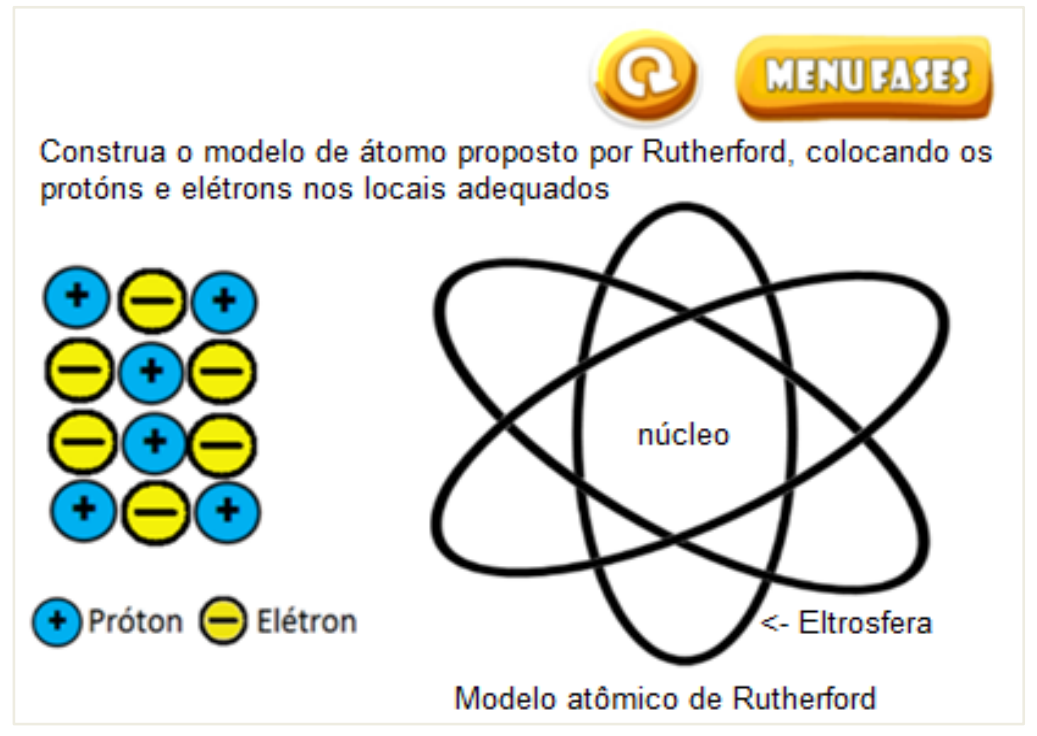

Fonte: autores 
$\mathrm{Na}$ fase apresentada na Figura 6 os alunos devem perceber que as cargas positivas são prótons e as negativas são elétrons, e que ambos se encontram em posições diferentes na estrutura atômica. Os efeitos são os mesmos observados no modelo 2, portanto, quando os prótons e elétrons forem colocados nos locais coretos será notado um "brilho".

Na Figura 7 a seguir encontra-se o modelo atômico de Bohr, que é o mais completo e estruturado. Nessa fase o aluno deve perceber que os elétrons se localizam na eletrosfera, e que está se divide em camadas de níveis energéticos. Cada camada comporta um número específico de elétrons. Os prótons e nêutrons encontram-se no núcleo. O efeito de "brilho" também está presente nessa fase.

Figura 7 - Template do modelo atômico 4

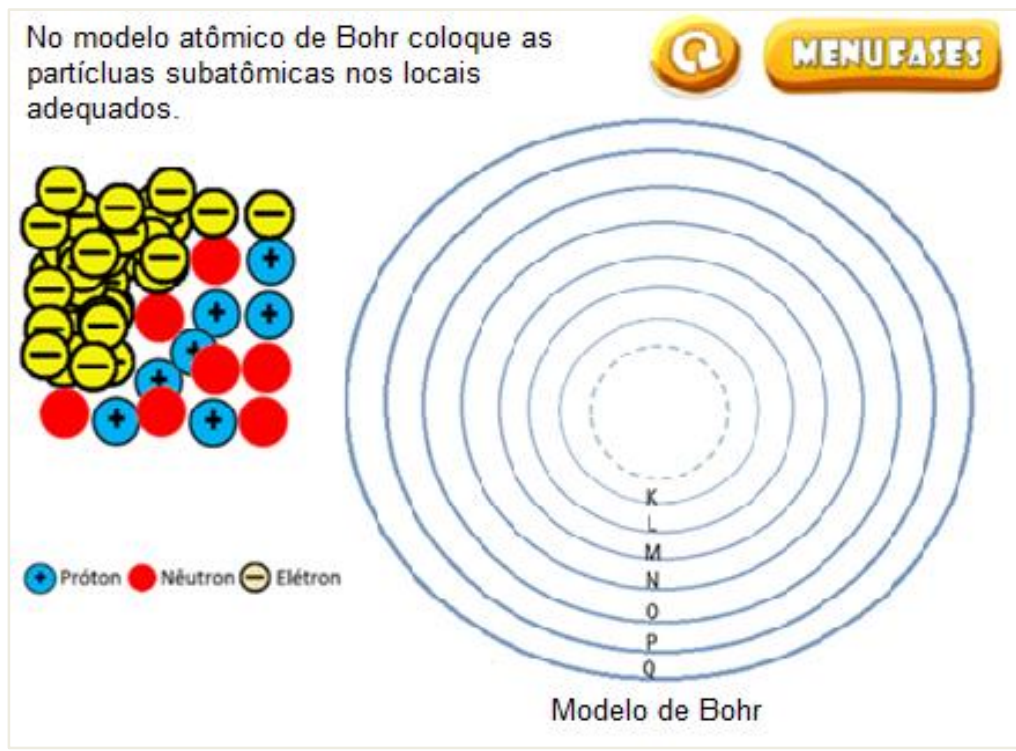

Fonte: autores

No momento em que os aprendizes interagem com a fase de treino eles aprendem sobre a estrutura atômica e os componentes do átomo. Além disso, eles também podem repetir quantas vezes for necessário a fase, basta que clique no botão repetir, que está simbolizado com uma seta curvada.

\section{OS SUJEITOS DA PESQUISA}

O trabalho foi realizado em uma escola pública de ensino médio, escola Professora Adelaide Tavares de Macedo, localizada no munícipio de Manaus, estado do Amazonas. A escola funciona nos turnos matutino e vespertino. Foram escolhidos alunos do turno matutino, matriculados no primeiro ano do ensino médio. 
A seleção dos sujeitos foi realizada mediante dois momentos: o $1^{\circ}$ momento ocorreu no dia 06 de fevereiro de 2019, período em que foi realizado a apresentação do projeto de pesquisa e dos critérios de participação (alunos regulamente matriculados e que possuíssem aparelhos celulares com o sistema operacional ANDROID); convite e seleção aleatória simples, realizada por sorteio (20 alunos participaram do sorteio); e entrega do TCLE (Termo de Consentimento Livre e Esclarecido) para os alunos sorteados.

No $2^{\circ}$ momento, realizado em 08 de fevereiro de 2019, foram recolhidos e analisados os TCLE, após realizou-se a seleção dos alunos, sendo selecionados apenas os alunos que entregaram os documentos assinados. Como resultado tivemos dezesseis alunos, posteriormente denominados de: A1, A2, A3, A4, A5, A6, A7, A8, A9, A10, A11, A12, A13, A14, A15 e A16.

\section{COLETA DE DADOS}

A coleta de dados ocorreu em três datas, como segue:

1. Aplicação individual da entrevista semiestruturada (13/02/2019);

2. Registro da atividade colaborativa no diário de pesquisa (15/02/2019);

3. Reaplicação individual da entrevista semiestruturada (22/02/2019);

De acordo com Pádua (2016) a entrevista semiestruturada, apresenta um conjunto de questões sobre o tema que está sendo estudado, e permite que o entrevistado fale livremente sobre assuntos que vão surgindo no momento da entrevista, é uma técnica eficiente e possibilita que os dados sejam analisados qualitativamente.

A entrevista semiestruturada foi aplicada de forma individual, numa sala de aula isolada. As questões investigadas foram:

1. Cite os modelos atômicos;

2. Cite os três componentes básicos do átomo;

Para a questão um foi disponibilizado uma folha de papel aos alunos, para que eles desenhassem os modelos atômicos, caso quisessem.

A reaplicação da entrevista semiestruturada foi posto em prática sem que os alunos soubessem, para evitar ansiedade e memorização dos modelos.

A atividade colaborativa foi registrada em um diário de pesquisa que "[...] é um caderno de campo próprio para registrar os acontecimentos observados, como: 
manifestações de comportamento, conversas, desenvolvimento das atividades e rotinas" (PÁDUA, 2016, p. 80).

Nesse diário os registros foram organizados por equipe e hora cronometrada, levou-se em consideração as seguintes observações: interação entre os pares, pedido de ajuda ou orientação ao mediador sobre como utilizar o jogo, tipo de interesse demonstrado durante a jogabilidade, tipo de interesse na colaboração e finalização da atividade.

\section{ATIVIDADE COLABORATIVA}

Na atividade colaborativa, realizada em 15 de fevereiro de 2019, os alunos se organizaram em equipes de no mínimo 2 e máximo 4 integrantes.

Diante disso, foi acordado que cada equipe definisse um representante (ou líder), que por sua vez tivesse obtido bons resultados na primeira aplicação da entrevista semiestruturada, essa ação foi necessária para que houvesse auxilio durante a atividade colaborativa e para que os alunos interagissem entre si.

As equipes formadas são apresentadas no Quadro 1 a seguir.

Quadro 1 - Relação de alunos por equipe

\begin{tabular}{|c|c|}
\hline Equipe & Alunos \\
\hline 1 & A1, A2, A3 e A4 \\
\hline 2 & A5 e A6 \\
\hline 3 & A7 e A8 \\
\hline 4 & A9, A10 e A11 \\
\hline 5 & A12, A13 e A14 \\
\hline 6 & A15 e A16 \\
\hline
\end{tabular}

Fonte: Autores

Como regra para atividade colaborativa, foi pedido aos alunos para lerem as instruções disponíveis no jogo Top Model Atomic, na área denominada apresentação, assim como prestar atenção nas informações e obedecer a ordem das fases de treino durante a jogabilidade, ou seja, começar pelo modelo 1 , seguido do modelo 2 , depois o modelo 3 e por último o modelo 4. Além disso, foi orientado para que eles buscassem esclarecer as dúvidas entre si, para estimular a discussão, proatividade, ajuda em equipe e aprendizado dos modelos atômicos. 
Tempo de duração: a atividade colaborativa durou cerca de 1 hora e 40 minutos, dois tempos de aula. Primeiramente os alunos organizaram suas equipes, depois o professor orientador disponibilizou o jogo por bluetoof para os líderes, que compartilharam com seus integrantes nos primeiros 10 minutos de atividade.

\section{DISCUSSÃO DOS RESULTADOS}

O resultado da verificação dos conhecimentos prévios dos alunos acerca do conteúdo de modelos atômicos, observado na entrevista semiestruturada, é apresentado na Tabela 1 a seguir.

Tabela 1 - Resultado da entrevista semiestruturada

\begin{tabular}{c|c|c}
\hline Aluno & $\begin{array}{c}\text { Quais são os 4 modelos } \\
\text { atômicos? }\end{array}$ & $\begin{array}{c}\text { Quais os componentes do } \\
\text { átomo? }\end{array}$ \\
\hline A1 & Rutherford & Prótons, nêutrons e elétrons \\
\hline A2 & $\begin{array}{c}\text { Dalton, Thomson, Rutherford e } \\
\text { Bohr }\end{array}$ & Elétrons e Nêutrons \\
\hline A3 & Dalton, Thomson, Rutherford & Elétrons e Nêutrons \\
\hline A4 & Não respondeu & Não respondeu \\
\hline A5 & Dalton e Thomson & Prótons, nêutrons e elétrons \\
\hline A6 & Não respondeu & Não respondeu \\
\hline A7 & Não respondeu & Não respondeu \\
\hline A8 & Não respondeu & Não respondeu \\
\hline A9 & Thomson e Rutherford & Não respondeu \\
\hline A10 & Dalton, Thomson e Rutherford & Não respondeu \\
\hline A11 & Rutherford & Não respondeu \\
\hline A12 & Não respondeu & Não respondeu \\
\hline A13 & Não respondeu & Não respondeu \\
\hline A14 & Rutherford & Prótons e elétrons \\
\hline A15 & Não respondeu & Não respondeu \\
\hline A16 & Thomson, Rutherford e Bohr & Não respondeu \\
\hline & & Fonte: Autores
\end{tabular}

Os modelos atômicos são conhecidos como modelo de Dalton, Thomson, Rutherford e Bohr. De acordo com a Tabela 1 dos 16 alunos investigados 7 não souberam citar quais são os modelos atômicos, oito alunos citaram de 1 a 3 modelos e apenas o aluno A2 citou os quatro modelos atômicos. 
Os três componentes básicos de um átomo são: prótons, elétrons e nêutrons, a Tabela 1 mostra que 11 alunos apresentaram dificuldade e não souberam responder e, apenas 5 alunos souberam citar corretamente alguns dos componentes, são eles os alunos A2, A3, A5, A11 e A14.

Por meio da análise dos resultados é observado que a maioria dos alunos conhecem alguns modelos atômicos, porém o aprendizado ainda não se concretizou, pois, ao observar os componentes básicos do átomo a maioria apresentou dificuldade em responder. Essa primeira análise revela que apenas os alunos A2, A3, A5, A9, A10 e A16 sabem, pelo menos, 2 modelos atômicos. E que os alunos A2, A3, A5, A11 e A14 tem conhecimento de no mínimo dois componentes básicos do átomo. Somente os alunos A2 e A3 possuem um conhecimento correto em relação a atomística, o que remete que o aprendizado aconteceu na série anterior e que se desenvolveu na ZDR.

A aplicação da atividade colaborativa ocorreu num segundo momento, em outra aula, e se mostrou eficiente, pois os alunos interagiram entre si, os que tinha uma boa noção do conteúdo colaboraram com o aprendizado dos colegas que apresentavam dificuldades. Além disso, todos seguiram as regras propostas, fizeram o bom uso do Top Model Atomic, repetindo a fase de treino inúmeras vezes e se esforçaram para entender o conteúdo proposto.

A Figura 8 a seguir apresenta um momento de interação em uma das equipes, observada durante o desenrolar da atividade colaborativa.

Figura 8 - Momento da atividade colaborativa com jogo móvel

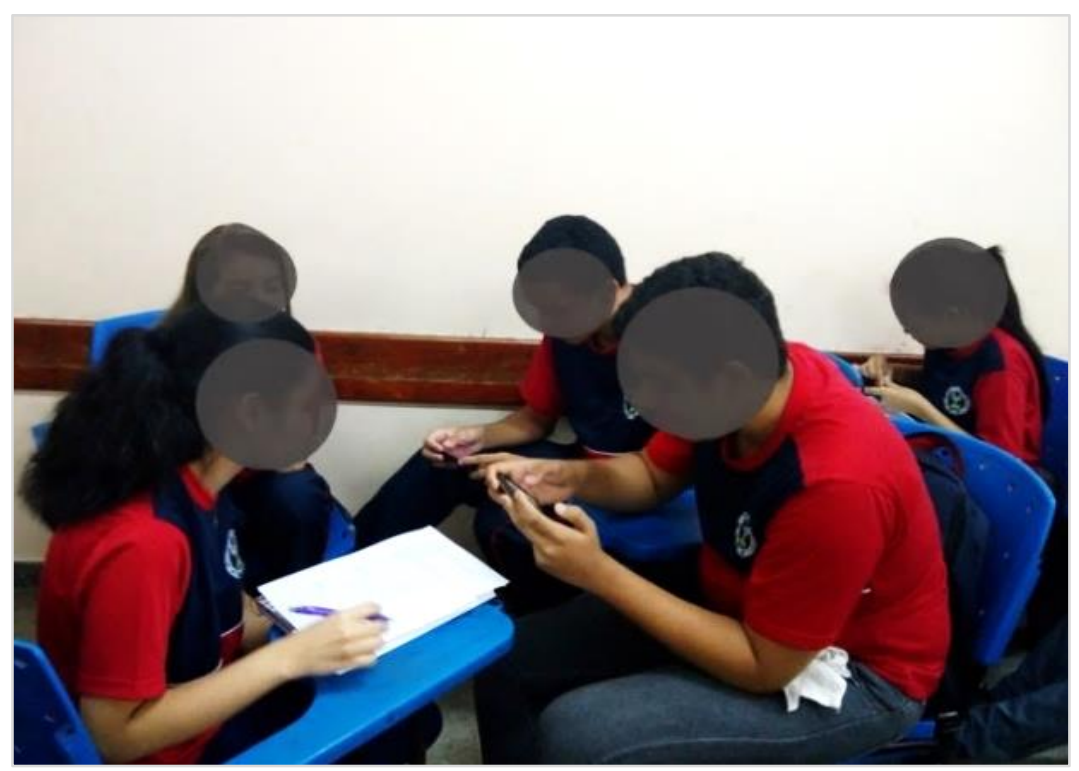

Fonte: autores 
Para verificar o processo de interação dos integrantes nos grupos durante a atividade colaborativa, foi orientado aos representantes que anotassem em uma folha a parte sobre o desempenho da equipe, as observações são apresentadas no Quadro 2 a seguir.

Quadro 2 - Comentários feitos pelos alunos durante a atividade colaborativa

\begin{tabular}{|c|c|}
\hline Equipe & Comentários \\
\hline 1 & $\begin{array}{l}\text { "Todos conseguiram aprender" } \\
\text { "Só um de nós teve dificuldade" }\end{array}$ \\
\hline 2 & $\begin{array}{l}\text { "A aluna } 5 \text { observou direitinho e conseguiu uma boa vitória, e } \\
\text { se saiu bem na construção dos modelos" } \\
\text { "No modelo atômico } 3 \text { o aluno } 5 \text { ela teve êxito e conseguiu um } \\
\text { bom número de acertos" } \\
\text { "No modelo } 4 \text { ela teve um pouco de dificuldade" }\end{array}$ \\
\hline 3 & $\begin{array}{c}\text { "A aluna } 8 \text { montou todos os modelos, o aluno } 7 \text { o ajudou" } \\
\text { "No modelo } 3 \text { a aluna } 8 \text { teve dificuldade, mas o aluno } 7 \\
\text { conseguiu e o ajudou novamente" } \\
\text { "No modelo } 4 \text { ninguém conseguiu ir muito bem" }\end{array}$ \\
\hline 4 & $\begin{array}{l}\text { "O aluno } 9 \text { logo percebeu que as bolas tinham que ficar no } \\
\text { círculo, o aluno } 11 \text { concordou e começou a levar os elétrons } \\
\text { em cada lugar" } \\
\text { "No modelo atômico } 3 \text {, o aluno } 9 \text { organizou tudo desde o } \\
\text { começo e explicou como fazer, ele já conhecia o modelo" } \\
\text { "No modelo atômico } 4 \text { o aluno } 9 \text { avaliou o modelo e percebeu } \\
\text { que os elétrons tinham que ficar ao redor de cada círculo; O } \\
\text { aluno } 11 \text { acha que os elétrons têm que ser numerados ao redor } \\
\text { do círculo. No final ele estava certo e todos começaram a fazer } \\
\text { a contagem." }\end{array}$ \\
\hline 5 & $\begin{array}{c}\text { "O aluno } 13 \text { entendeu os modelos e explicou para todos, ele } \\
\text { foi bem em tudo, o aluno } 14 \text { teve um pouco de dificuldade } \\
\text { apenas nas posições" }\end{array}$ \\
\hline 6 & $\begin{array}{l}\text { "No modelo atômico } 2 \text {, o aluno } 16 \text { entendeu que os elétrons } \\
\text { negativos ficam dentro da bolinha, o aluno } 15 \text { não entendeu } \\
\text { porque o positivo não ficava dentro das bolinhas" } \\
\text { "No modelo atômico } 3 \text { todos perceberam que o elétron } \\
\text { negativo fica ao redor do centro núcleo" } \\
\text { "No modelo atômico } 4 \text { conseguimos colocar as bolas nas } \\
\text { posições certas" }\end{array}$ \\
\hline
\end{tabular}

Fonte: Autores 
A aprendizagem colaborativa pode ser descrita como uma abordagem que contribua com a construção de conhecimentos em grupos. Para existir colaboração é necessário que tenha duas ou mais pessoas, a mediação de um tutor, de forma a somente orientar quanto às regras e um instrumento didático que propicie a interação entre pares (MOURA, 2015). Geralmente, essa abordagem permite que os alunos aprendam de forma interativa, por meio de da busca de soluções para situações problematizadoras, assim eles acabam interagindo na construção do conhecimento e no desenvolvimento das suas habilidades intelectuais (MACHADO et al., 2016).

São princípios da aprendizagem colaborativa (BARKLEY et al., 2014): (1) divisão de atividades e padrões de interação; (2) ocorrência de interações entre alunos e grupos e (3) a existência de um ambiente que propicie a criação de um modelo mutualmente aceito.

E como pode ser constatado no Quadro 2 os alunos interagiram e auxiliaram uns aos outros durante a atividade colaborativa.

Diante dos comentários podemos considerar que houve colaboração nas equipes 3, 4, 5 e 6. Podemos conferir também a percepção deles diante dos efeitos lúdicos e sonoros do jogo, que foram essenciais para que percebessem o lugar correto para posicionar as partículas subatômicas.

Por exemplo, na fala do grupo 6 "No modelo atômico 2, o aluno 16 entendeu que os elétrons negativos ficam dentro da bolinha, porém o aluno 15 não entendeu porque o positivo não ficava dentro das bolinhas", aqui é possível observar a percepção deles em saber que o elétron é negativo e a dúvida sobre o porquê o próton deve ser posicionado fora da bolinha. Ainda na mesma equipe, no modelo atômico 3 todos perceberam que o elétron negativo fica ao redor do núcleo.

No grupo 4, também são observados interações e questionamentos, mas agora é no modelo 4, e no final os alunos compreendem que no modelo de Bohr os elétrons estão organizados em camadas, e que se posicionam fora do núcleo.

Além disso, durante a atividade colaborativa os alunos demonstraram interesse no jogo e questionavam algumas ações quando experimentavam dificuldade. A princípio eles eram orientados a tentarem descobrir, quando não o conseguiam o professor pesquisador os questionavam e ofereciam dicas. Em nenhum momento a resposta foi cedida. 
Num terceiro momento foi realizada a reaplicação da entrevista semiestruturada, os resultados são apresentados na Tabela 2 a seguir.

Tabela 2 - Resultado da reaplicação da entrevista semiestruturada

\begin{tabular}{|c|c|c|}
\hline Aluno & $\begin{array}{c}\text { Quais são os } 4 \text { modelos } \\
\text { atômicos? }\end{array}$ & $\begin{array}{c}\text { Quais os componentes } \\
\text { do átomo? }\end{array}$ \\
\hline $\mathrm{A} 1$ & Não respondeu & $\begin{array}{c}\text { Prótons, nêutrons e } \\
\text { elétrons }\end{array}$ \\
\hline $\mathrm{A} 2$ & $\begin{array}{c}\text { Dalton, Thomson, Rutherford } \\
\text { e Bohr }\end{array}$ & $\begin{array}{c}\text { Prótons, nêutrons e } \\
\text { elétrons }\end{array}$ \\
\hline A3 & $\begin{array}{c}\text { Dalton, Thomson, Rutherford } \\
\text { e Bohr }\end{array}$ & $\begin{array}{c}\text { Prótons, nêutrons e } \\
\text { elétrons }\end{array}$ \\
\hline A4 & $\begin{array}{c}\text { Dalton, Thomson, Rutherford } \\
\text { e Bohr }\end{array}$ & Não respondeu \\
\hline A5 & $\begin{array}{c}\text { Dalton, Thomson, Rutherford } \\
\text { e Bohr }\end{array}$ & Não respondeu \\
\hline A6 & Dalton & $\begin{array}{c}\text { Prótons, nêutrons e } \\
\text { elétrons }\end{array}$ \\
\hline A7 & $\begin{array}{c}\text { Dalton e Thomson, } \\
\text { Rutherford }\end{array}$ & $\begin{array}{c}\text { Prótons, nêutrons e } \\
\text { elétrons }\end{array}$ \\
\hline A8 & $\begin{array}{l}\text { Dalton e Thomson, } \\
\text { Rutherford }\end{array}$ & $\begin{array}{c}\text { Prótons, nêutrons e } \\
\text { elétrons }\end{array}$ \\
\hline A9 & $\begin{array}{c}\text { Dalton, Thomson, Rutherford } \\
\text { e Bohr }\end{array}$ & $\begin{array}{c}\text { Prótons, nêutrons e } \\
\text { elétrons }\end{array}$ \\
\hline A10 & Não respondeu & Não respondeu \\
\hline A11 & $\begin{array}{c}\text { Dalton e Thomson, } \\
\text { Rutherford }\end{array}$ & $\begin{array}{c}\text { Prótons, nêutrons e } \\
\text { elétrons }\end{array}$ \\
\hline A12 & $\begin{array}{c}\text { Dalton, Thomson, Rutherford } \\
\text { e Bohr }\end{array}$ & Elétrons e nêutrons \\
\hline A13 & $\begin{array}{c}\text { Dalton, Thomson, Rutherford } \\
\text { e Bohr }\end{array}$ & $\begin{array}{c}\text { Prótons, nêutrons e } \\
\text { elétrons }\end{array}$ \\
\hline A14 & Não respondeu & $\begin{array}{c}\text { Prótons, nêutrons e } \\
\text { elétrons }\end{array}$ \\
\hline A15 & $\begin{array}{c}\text { Dalton, Thomson, Rutherford } \\
\text { e Bohr }\end{array}$ & Prótons e elétrons \\
\hline A16 & $\begin{array}{c}\text { Dalton, Thomson, Rutherford } \\
\text { e Bohr }\end{array}$ & Prótons e elétrons \\
\hline
\end{tabular}

Fonte: Autores 
A análise dos resultados revela que ocorreu aprendizado. De acordo com a Tabela 2, dos 16 alunos investigados 13 conseguiram citar pelo menos um modelo atômico, e apenas três alunos não souberam responder, foram eles os alunos A1, A10 e A14.

Em relação a pergunta "Quais os componentes dos átomos”, dessa vez 13 alunos souberam citar pelo menos dois componentes básicos do átomo, e somente os alunos A4, A6 e A10 não souberam responder.

Para uma melhor observação e comparação dos resultados a Figura 9, a seguir, apresenta os resultados da aplicação da entrevista semiestruturada, antes e após a atividade colaborativa.

Figura 9 - Relação de acertos apresentados na entrevista semiestruturada, antes e após a atividade colaborativa (AC)

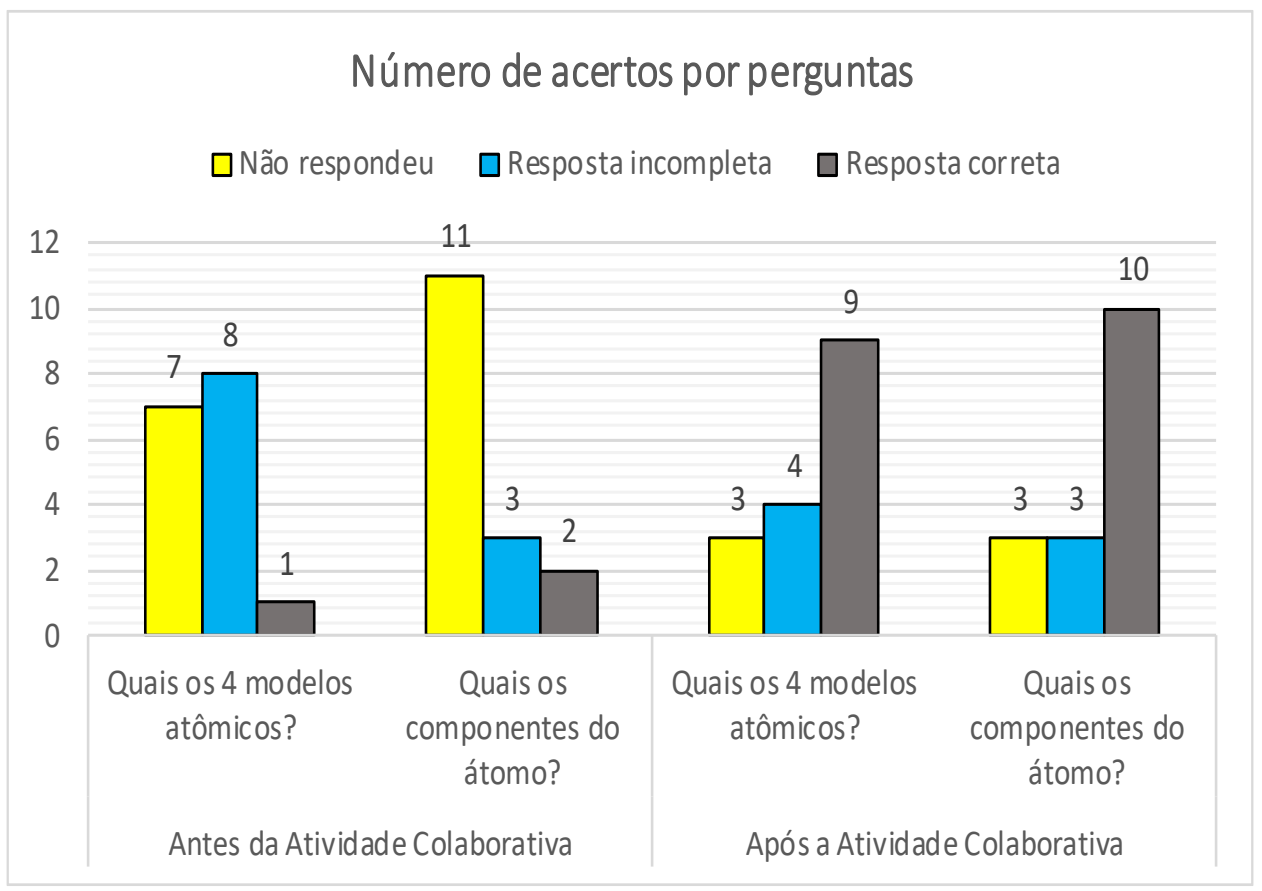

Fonte: autores

A Zona de Desenvolvimento Proximal (ZDP) relaciona o que o estudante realizou sozinho e o que ele é capaz de aprender com a colaboração de uma pessoa com mais experiência. A ZDP pode ser verificada no momento em que os alunos montam os modelos atômicos e colocam as estruturas subatômicas nos seus devidos lugares, utilizando instruções como mediadoras para realizar a atividade.

Ao observar a Figura 9 deduz-se que a ZDR foi desenvolvida, pois nela estão presentes os conhecimentos que foram aprendidos, e ao se comparar o antes com o depois é perceptível o grande número de acertos após a atividade colaborativa. Isso se dá ao 
exercício e treino na montagem dos modelos no jogo móvel, que contribuiu para o desenvolvimento de novas habilidades e das ZDP e ZDPT.

Araújo (2016) cita que os jogos quando aplicados num ambiente colaborativo permite maior interação entre os alunos, fazendo-os utilizar estratégias para a realização das atividades, além de contribuir para o desenvolvimento de habilidades e da atenção (REIS et al., 2016).

\section{CONSIDERAÇÕES FINAIS}

Os jogos para dispositivos móveis possuem características lúdicas e atrativas, essas características quando somadas a um contexto colaborativo estimulam o processo de ensino e aprendizagem, que por sua vez acionam a ZDP e, consequentemente, as ZDPT e ZDR.

A partir do mapeamento de pesquisas com jogos móveis e atividades que envolvesse colaboração, foi possível planejar como se daria o desenvolvimento da ZDP durante uma atividade com jogo móvel de química. A partir da pesquisa realizada, foi possível desenvolver o jogo Top Model Game para ser aplicado numa atividade colaborativa e assim identificar as zonas de aprendizagem.

Os resultados apontam que o jogo contribuiu para o ensino dos modelos atômicos e com o entendimento dos tipos de partículas, além do mais, a atividade colaborativa permitiu a comunicação, socialização e assistência entre os sujeitos. Embora a verificação do aprendizado acerca do conteúdo de química tenha sido observada na entrevista semiestruturada, os aspectos participativos foram notados durante a prática em grupo.

Diante do exposto, compreende-se a necessidade de explorar outros tipos de temáticas na disciplina de química, principalmente os considerados complexos para os estudantes do nível médio. $\mathrm{O}$ estudo apresentou algumas lacunas em relação a acessibilidade para alunos surdos e na investigação no processo de aprendizagem para os que não conseguiram aprender, indicando a relevância de novas investigações quanto à estrutura do jogo e na análise dos sujeitos pesquisados.

Por conseguinte, essa pesquisa auxiliou na criação de uma ferramenta didática, na investigação quanto ao uso para o ensino de modelos atômicos, assim como na contribuição para o desenvolvimento das zonas reais, proximais e potenciais dos alunos, que se deu durante o desenrolar de uma experiência colaborativa. Essa ação pedagógica pode ser inserida sem grandes complicações nas escolas públicas, viabilizando a produção 
e utilização de novos recursos tecnológicos, estimulando os alunos a serem proativos e autônomos.

\section{REFERÊNCIAS}

ALL, A; CASTELLAR, E. P. N; VAN LOOY, J. Towards a conceptual framework for assessing the effectiveness of digital game-based learning. Computers \& Education, v. 88, p. 29-37, abr. 2015.

BARKLEY, E. F.; CROSS, K. P.; MAJOR, C. H. Collaborative learning techniques: A handbook for college faculty. John Wiley \& Sons, 2014.

BARMA, S; DANIEL, S; BACON, N; GINGRAS, M. A; FORTIN, M. Observation and analysis of a classroom teaching and learning practice based on augmented reality and serious games on mobile platforms. International Journal of Serious Games. v. 2, n. 2, p. 69-88, jun. 2015.

BROWN, T. L; LEMAY, E. H; BURSTEN, B. E. Química, a ciência central. Tradutor: Robson Matos. São Paulo: Prentice Hall, 2005.

DIAS, N; ANDRADE, M; ROSALEN, M. Utilização de jogo digital no processo de ensino e aprendizagem de Ciências. X Encontro Nacional de Pesquisa em Educação em Ciências (X ENPEC) - Águas de Lindóia, SP, v. 10, nov. 2015. Disponível em: http://www.abrapecnet.org.br/enpec/x-enpec/anais2015/busca.htm Acesso em: 05 de jan. 2020.

GODOY, A. S. Introdução à pesquisa qualitativa e suas possibilidades. Revista de Administração de Empresas, São Paulo, v. 35, n. 2, p. 57-63, abr. 1995.

KYRIAKIDES, A. O; MELETIOU-MAVROTHERIS, M; PRODROMOU, T. Mobile technologies in the service of students' learning of mathematics: the example of game application ALEX in the context of a primary school in Cyprus. Mathematics

Education Research Journal, v. 28, n. 1, p. 53-78, dez. 2016.

MACHADO, L. D. P; BERKENBROCK, C. D. M; SIPLE, I. Z; HIRATA, C. M. Uma abordagem colaborativa para aprendizagem de programação orientada a objetos. In:

Anais Principais do XIII Simpósio Brasileiro de Sistemas Colaborativos (SBSC) Belém, Jul. 2016. Disponível em:

https://sol.sbc.org.br/index.php/sbsc/article/view/9510 Acesso em: 03 de ago. 2019.

MOORE, A; GOULDING, J; BROWN, E; SWAN, J. AnswerTree - a hyperplace-based game for collaborative mobile learning. In: Proceedings of the mLearn 2009

Conference, Orlando, Florida, USA, Oct. 2009. Disponível em:

http://oro.open.ac.uk/29888/ Acesso em: 12 de Fev. 2020. 
MOURA, E. R. S. Uma ferramenta colaborativa móvel para apoiar o processo de ensino-aprendizagem da Língua Portuguesa para alunos surdos. Dissertação (Mestrado em Informática) - Universidade Federal do Amazonas, Manaus/AM. 2015.

NAISMITH, L; SHARPLES, M; VAVOULA, G; LONSDALE, P. Literature review in mobile technologies and learning. A NESTA: Futurelab Series, University of Birmingham - Report 11, 2004.

OLIVEIRA, M. K. Vygotsky: aprendizado e desenvolvimento, um processo sócio histórico. São Paulo. Editora Scipione, 1997.

PÁDUA, E. M. M de. Metodologia da pesquisa: abordagem teórico-prática. Campinas, SP: Papirus, 2016.

ROMERO, M; USART, M; OTT, M; EARP, J. Learning through playing for or against each other? Promoting collaborative learning in digital game based learning. Learning. In: European Conference on Information Systems (ECIS). 2012. Disponível em: https://aisel.aisnet.org/ecis2012/93/ Acesso em: 10 de Fev. 2020.

SCHAEFFER, A. G; ANGOTTI, J. A. P. Jogos digitais na apropriação de conhecimentos científicos. Revista Novas Tecnologias na Educação (RENOTE), Rio Grande do Sul, v. 14, n. 1, p. 1-10, jul. 2016.

TRONCARELLI, M. Z; FARIA, A. A. A aprendizagem colaborativa para a interdependência positiva no processo ensino-aprendizagem em cursos universitários. Educação (UFSM), Santa Maria, v. 39, n. 2, p. 427-444, maio/ago. 2014.

VYGOTSKY, L. Interaction between learning and development. Readings on the Development of Children, v. 23, n. 3, p. 34-41, 1978.

ZANELLA, A. V. Zona de desenvolvimento proximal: análise teórica de um conceito em algumas situações variadas. Temas da psicologia, Ribeirão Preto, v. 2, n. 2, p.97110, ago. 1994. 